\title{
Land Subsidence and Uplift Surveying by Synthetic Aperture Radar Interferometry in Lianjiang Plain
}

\author{
Ling Zhang, Daqing Ge, Man Li, Bin Liu, Xiaofang Guo, ${ }^{*}$ and Qiong Wu \\ China Aero Geophysical Survey and Remote Sensing Center for Natural Resources, Beijing 10083, China
}

(Received September 25, 2020; accepted November 18, 2020)

Keywords: land subsidence, InSAR, groundwater exploitation, uplift, ground fissures

In order to investigate the distribution of land subsidence in the Lianjiang Plain, the interferometric point target analysis (IPTA) method has been carried out with RADARSAT-2 data in this work. It was found that large-scale land uplift occurred in Puning City and Shantou City, and the maximum rebound velocity exceeded $100 \mathrm{~mm} / \mathrm{a}$ in 2019. Then, the Sentinel-1 data collected from June 2015 to November 2019 were used to carry out a long-term sequence inversion of the ground rebound zone and further verify the RADARSAT-2 monitoring results. The results of both kinds of data show the similar distribution characteristics of the two uplift zones. After the preliminary analysis of interferometric synthetic aperture radar (InSAR) results, geological data, and local government reports, the major factor causing land subsidence and uplift was concluded to be the change in groundwater level. The thick Quaternary strata and the compressible/expandable soil layers provide conditions for rapid subsidence and uplift. Also, the south edge of each uplift zone is limited by the WNW-trending Puning-Tianxin fault, where the land deformation is accompanied by ground fissures.

\section{Introduction}

Land subsidence is a phenomenon that the elevation of the ground in the vertical direction changes due to the exploitation of underground resources or a change in stratum structure. ${ }^{(1-3)}$ It is a slowly evolving geological disaster that threatens the viability and sustainability of economic development. At present, there are more than 50 cities in China suffering from land subsidence, causing direct economic losses of tens of billions of yuan each year. The total area with cumulative subsidence exceeding $200 \mathrm{~mm}$ is more than $79000 \mathrm{~km}^{2}$. (4) In these subsidence areas, the overexploitation of underground water for industry and agriculture is the main cause of regional land subsidence. In order to reduce the hazards of land subsidence, a variety of control measures have been adopted, among which the effect of prohibiting and restricting groundwater extraction is the most significant. The groundwater level has dropped more slowly and recovered in some areas where measures to control ground subsidence have been implemented. However, in some areas of southern China with groundwater exploitation

*Corresponding author: e-mail: guoxiaofang@mail.cgs.gov.cn https://doi.org/10.18494/SAM.2020.3117 
management, ground uplift has been triggered. Ground uplift is also a slowly evolving geological disaster. $^{(1,5)}$ When ground fissures occur with ground uplift, the impact of ground uplift is more obvious. Ground fissures further aggravate damage to the land surface, which may damage the structures of buildings, reduce the bearing capacity of foundations, and cause problems such as flooding in the basements of buildings.

InSAR has been the main technology to survey and monitor regional land subsidence in China. InSAR uses the geometric relationship between sensors and ground objects to obtain large-scale, high-precision three-dimensional information and surface morphological changes. Radar differential interferometry (D-InSAR) technology is a further improvement of InSAR technology for obtaining surface deformation. It can also be considered as an extension of InSAR technology for obtaining information on surface changes, and its accuracy can reach centimeter level or higher. ${ }^{(6-8)}$ After decades of technical development and engineering applications, it has been proved that InSAR technology has a wide coverage, short measurement time, and high accuracy and can overcome the traditional measurement deficiencies resulting from the weather, topography, and human factors. ${ }^{(9-11)}$

In this study, 14 RADARSAT-2 images taken from December 2018 to November 2019 were used to survey the land deformation of the Lianjiang Plain in Guangdong Province based on the time series InSAR analysis method. The results show that there are two obvious ground rebound zones with areas of 56 and $13 \mathrm{~km}^{2}$, and the maximum annual rebound rate exceeded $10 \mathrm{~mm} / \mathrm{a}$. The land uplift was induced by the ban and restriction of groundwater use, and the rebound speed for such a large area is the highest in eastern China. The spatial characteristics of rebound are related not only to the thickness distribution of the Quaternary strata, but also to the distribution of faults. Then, the Sentinel-1 SAR data collected over more than 4 years from June 2015 to October 2019 were used to verify the ground uplift and obtain the history of ground deformation. Finally, the mechanism inducing the regional land deformation was preliminarily analyzed.

\section{InSAR Deformation Survey Technology}

In this work, the interferometric point target analysis (IPTA) method developed by GAMMA Remote Sensing, which is based on multiple master images with small spatial and temporal baselines, was used. This method integrates the advantages of the small baseline subset (SBAS) and permanent scatterer interferometry (PSI) techniques for land deformation time series analysis. Using this method, land deformation analysis can also be effectively performed with a reduced set of data, minimizing the inaccurate external digital elevation model (DEM) effect and the spatial and temporal decorrelation. Sections 2.1-2.3 describe the process flow (Fig. 1).

\subsection{Interferogram stack generation}

In this work, all the data pairs within a specific baseline have been combined to calculate the interferogram set. Precise orbit data are needed for SAR data co-registration, and external DEM is used for terrain phase calculation and geographic rectification. After the co-registration 


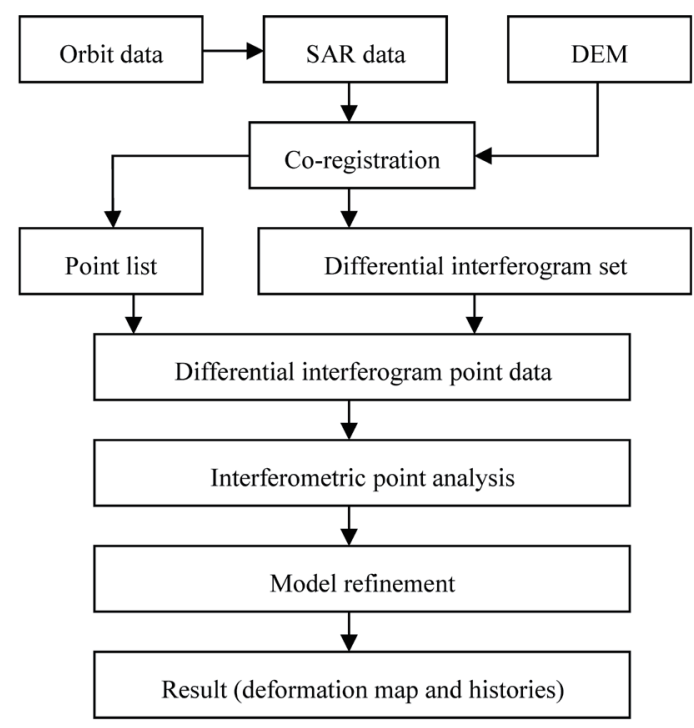

Fig. 1. Data process flow chart.

of SAR data and DEM, the interferometric phase is calculated by the conjugate multiplication of each pair of radar images, and the differential phase of each interferogram is obtained by the subtraction of terrain and flat phases in the image plane. The strategy of using multiple master images works with all available image pairs, in contrast to the use of one common master image in the traditional PSI technique. The use of multiple master images increases the number of interferograms used for phase regression, even with a small amount of SAR data. Moreover, the selection of a small orbital separation can minimize the effects of the DEM error and spatial decorrelation in differential interferograms, and enables more coherent targets to be preserved in the regression analysis. After the conventional D-InSAR process for each pair, the set of differential interferograms is prepared for the next step.

\subsection{Point list generation}

A key element of IPTA InSAR is that the interferometric analysis is only carried out for the selected targets. The intensity variability and spectral diversity criteria have been used jointly to identify the coherent targets from a stack of SAR single-look complex (SLC) images. ${ }^{(7)}$

Because the distributed targets do not show speckle behavior, whereas a single coherent scatterer dominates the echo, a significantly lower temporal variability is observed for point targets than for the distributed targets. In the intensity variability selection method, this characteristic is used to identify point target candidates in large SLC data stacks. As the measure of the temporal variability, the mean/sigma ratio is used, where the mean is the temporal average of the backscattering and sigma is the standard deviation of the backscattering. As a result, these single isolated scatterers smaller than the resolution can be recognized from a larger number of images by considering the intensity standard deviation of each pixel. Point targets with backscattering above the given threshold are selected. 
In the case of small SLC data stacks, the temporal variability criterion used to select point target candidates becomes unreliable for statistical reasons. For the spectral diversity criterion, only pixels whose energy remains approximately the same when processing different looks with fractional azimuth and range bandwidth are expected. A list of point target candidates for each SLC is generated by this method and is merged into a one-point candidate list.

These two point target candidate lists, derived from the intensity variability and spectral diversity criteria, are merged into the final coherent point target candidate list. Then, the differential interferometric phase for each point target candidate is generated from the twodimensional pixel data obtained in step 1.

\subsection{Deformation parameter estimation}

IPTA phase regression is performed to estimate the deformation parameters with the point stack of differential interferograms, which supposes that the deformation is linear, with the average deformation rate map as one of the results. The point candidates are related within a Delauney triangulation, with the selected points as the nodes related by arcs. The deformation and DEM error are estimated using a linear model. Actually, the surface subsidence is nonlinear as the groundwater level changes seasonally, which can be clearly seen when the differential interferograms are reviewed for error rejection. Once the linear terms of the deformation and DEM error have been estimated, by considering the different characteristics of the atmospheric distribution and the nonlinear deformation in time and space, their respective contributions to the phase can be separated with a combination of temporal and spatial filters. A time series of unwrapped deformation phases can be generated, given the multiple temporal reference stack of unwrapped phases primarily due to deformation. Then, the deformation history is extracted by the weighted least-squares method, including the linear and nonlinear components, taking the time interval as the weight value.

\section{Overview of Test Site and SAR Data}

\subsection{Test site}

The Lianjiang Plain is located in the southern part of the Chaoshan Plain in Guangdong Province, covering an area of more than $500 \mathrm{~km}^{2}$ (Fig. 2). The Chaoshan Plain is one of the Quaternary basins along the southeast coast of China. It not only has a large distribution area, but also has a large Quaternary sediment thickness (maximum thickness of $168 \mathrm{~m}$ ). Song et al. divided the Quaternary strata in the Lianjiang Plain into nine basic layers based on a drill histogram. ${ }^{(12)}$ The bottom stratum of the Quaternary strata is a Middle Pleistocene layer of continental sedimentary rock with a thickness of about $40 \mathrm{~m}$. The underpart of the basin belongs to the Medio-Pleistocene. The top part of the Medio-Pleistocene series is stable mottled clay with a thickness of about $10 \mathrm{~cm}$, which reflects the fact that there is a long sedimentary interruption between the Medio-Pleistocene and the Epipleistocene. The distribution of the Medio-Pleistocene series is limited to the area between Puning and Liangying, but the 


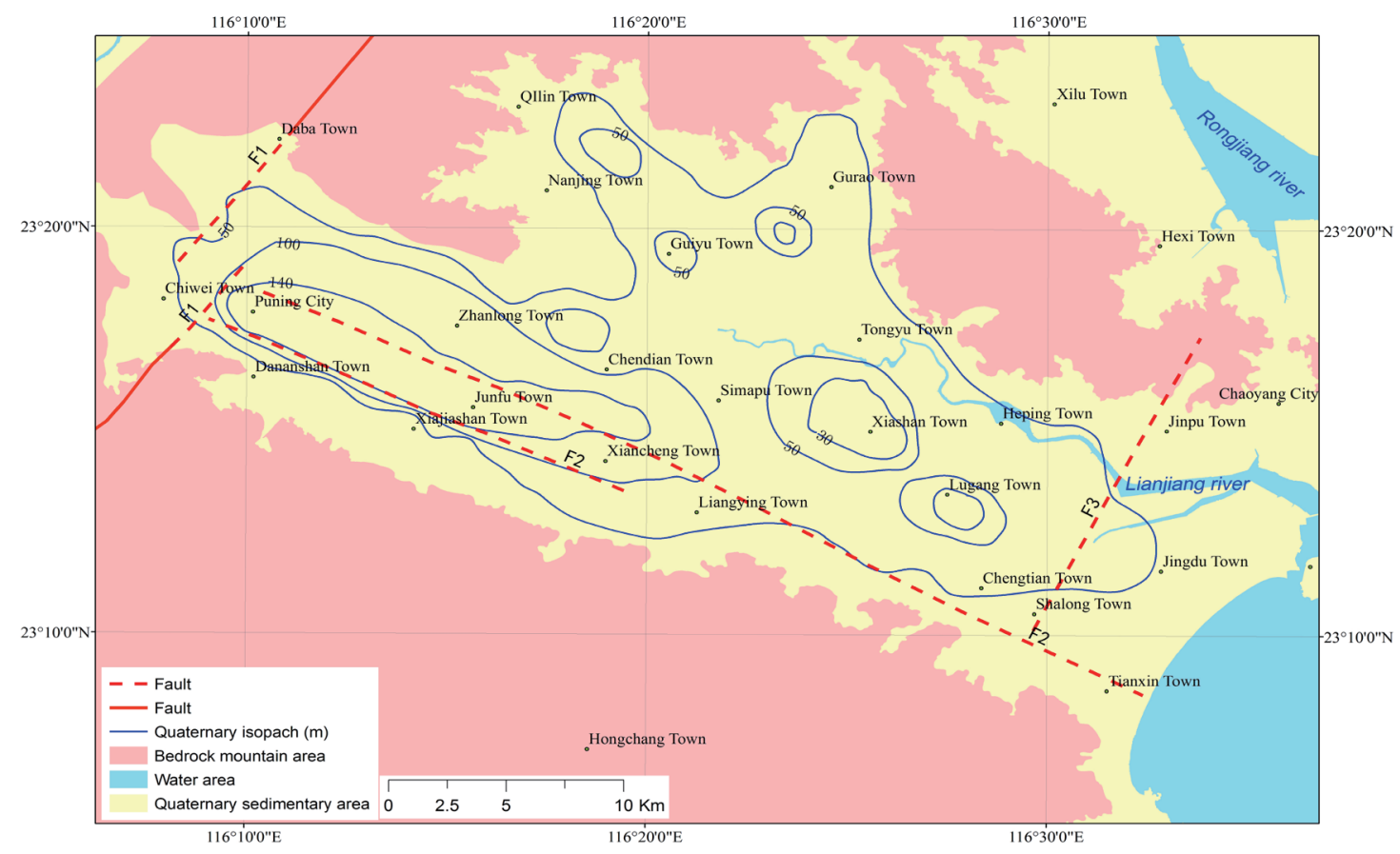

Fig. 2. (Color) Isopach of Quaternary strata and fault map of Lianjiang Plain (adapted from Fig. 1. in Ref. 12 and Fig. 1. in Ref. 13).

Epipleistocene and Holocene series occupy a larger part of the plain, indicating that part of the fault depression starts in the Medio-Pleistocene with a large amount of sediment incorporated since the Epipleistocene. ${ }^{(12)}$ The WNW-trending Puning-Tianxin fault (F2), NE-trending Puning-Chaozhou fault (F1), and Raoping-Huilai fault (F3) are located in the Lianjiang Plain. ${ }^{(13)}$

Water is a very scarce resource in the Lianjiang Plain, and the per capita surface water resource is only one-fifth of that of Guangdong Province. There are a large number of printing, dyeing, textile, paper, and other plants in the area with heavy water consumption. Since the beginning of this century, ground subsidence and ground fissures have successively appeared, seriously affecting the productivity and safety of residents. According to geological experts, they have mainly been caused by the overexploitation of groundwater, ${ }^{(14)}$ particularly by local private printing and dyeing enterprises, as pointed out clearly in the local government report of Chaonan District in 2011. This report proposed the strict control of the exploitation of groundwater, the strengthening of the monitoring of ground fissures, and the adoption of measures such as relocation and evasive action.

\subsection{SAR data}

Two kinds of data were used in this work, namely, RADARSAT-2 fine mode data of 5 $\mathrm{m}$ spatial resolution and $24 \mathrm{~d}$ revisiting time, and Sentinel-1 IW mode data of $30 \mathrm{~m}$ spatial resolution and $12 \mathrm{~d}$ revisiting time. 
The acquisition period of the 14 RADARSAT-2 images was from December 2018 to November 2019. Using the IPTA method, all 91 data pairs were used in the regression analysis of the coherent point target time series. The interferometric pairs of the RADARSAT-2 data combination are shown in Fig. 3(a). The subsidence rate from December 2018 to November 2019 was obtained.

The data acquisition period of the 114 Sentinel-1 images was from June 2015 to November 2019. There were 676 interferograms generated with a temporal baseline of 36 to $150 \mathrm{~d}$ and a spatial baseline of less than $80 \mathrm{~m}$. The interferometric pairs of the Sentinel-1 data combination are shown in Fig. 3(b). After the IPTA time series analysis, the land deformation time series from June 2015 to November 2019 and four annual deformation rate maps in 2016, 2017, 2018, and 2019 were calculated, which clearly revealed the deformation history of the two rebound areas of the Lianjiang Plain.

\section{Land Subsidence and Uplift}

\subsection{Regional land subsidence and uplift distribution}

The land deformation distribution acquired from the IPTA processing with RADARSAT-2 data in the Lianjiang Plain in 2019 is clearly shown in Fig. 4. Both land subsidence and land rebound occurred in the site. The color of the point targets in Fig. 4 indicates the land deformation rate in 2019, where a negative value indicates land subsidence and a positive value indicates ground uplift.

Large areas of slight subsidence and small centers with large subsidence can both be found in the Lianjiang Plain. The large regions of slight land subsidence are distributed along both banks of the Lianjiang River, with a subsidence rate below $30 \mathrm{~mm} / \mathrm{a}$ in Heping Town, Tongyu Town, Ximapu Town, and Chendian Town. There are three small subsidence centers, which are located in Xiancheng Town and the northwest and southeast of Gurao Town with a maximum subsidence rate of more than $50 \mathrm{~mm} / \mathrm{a}$.

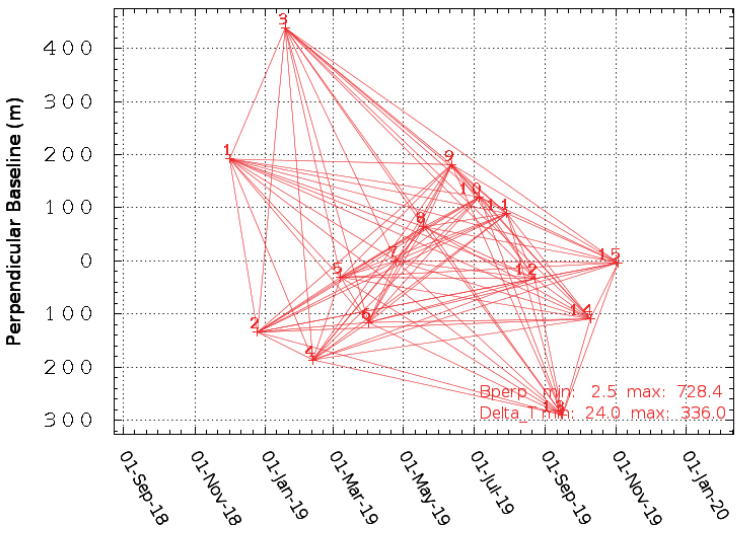

(a)

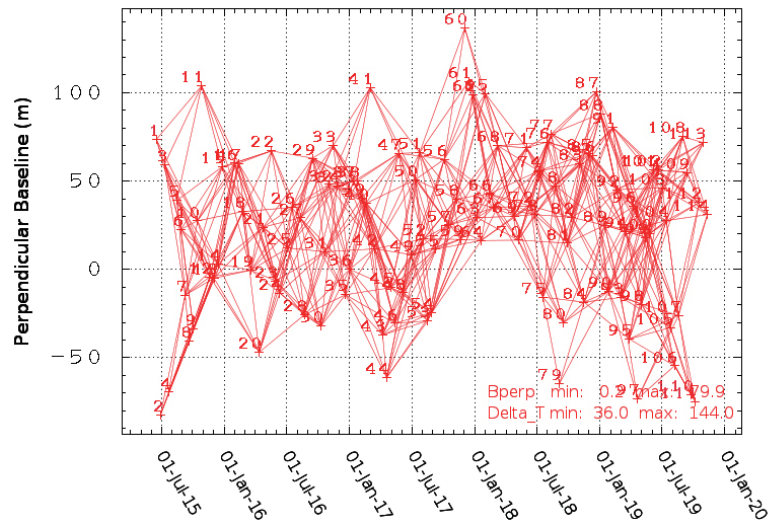

(b)

Fig. 3. (Color online) Baseline graphs used to calculate interferometric pairs for (a) RADARSAT-2 and (b) Sentinel-1. 


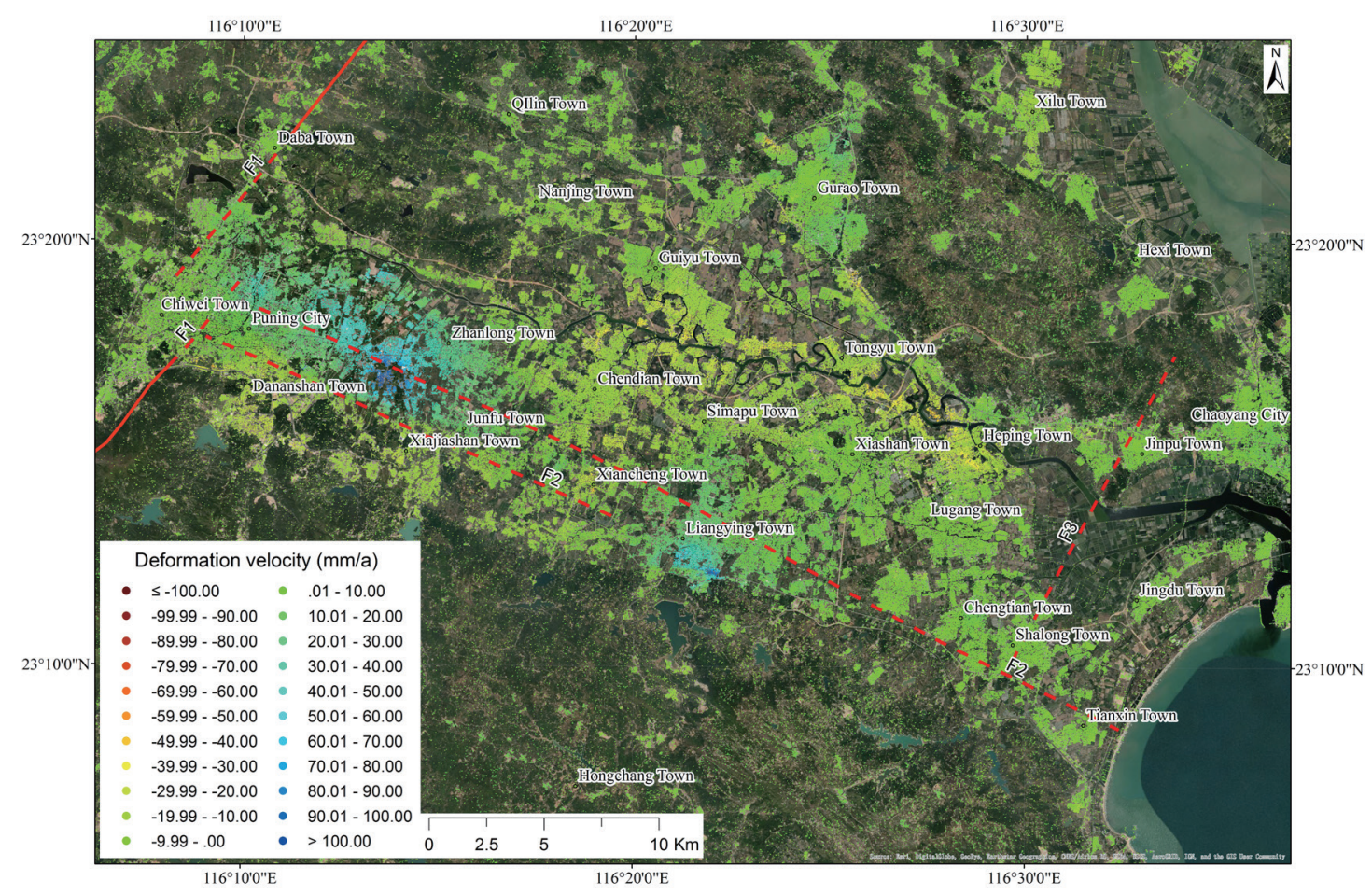

Fig. 4. (Color) Land deformation in Lianjiang Plain in 2019.

In addition, it can be seen from Fig. 4 that land uplift also occurred in the Lianjiang Plain in 2019. There are two significant regions of uplift centered on Puning City in Jieyang and Chaonan District in Shantou. The larger region, including parts of Puning City, Xiajiashan Town, Junbu Town, and Zhanlong Town, is located where the Quaternary strata have the greatest thickness in the Lianjiang Plain, with a maximum uplift velocity of $130 \mathrm{~mm} / \mathrm{a}$ in Shuangxi Village $\left(23^{\circ} 16^{\prime} 42.12^{\prime \prime} \mathrm{N}, 116^{\circ} 13^{\prime} 35.29^{\prime \prime} \mathrm{E}\right)$. This region of uplift has an area of $56 \mathrm{~km}^{2}$. The smaller region with an area of more than $13 \mathrm{~km}^{2}$ is located in Liangying Town in Chaonan District of Shantou, whose uplift rate is more than $80 \mathrm{~mm} / \mathrm{a}$ in Xincuo Community $\left(23^{\circ} 12^{\prime} 12.64^{\prime \prime} \mathrm{N}\right.$, $\left.116^{\circ} 21^{\prime} 57.27^{\prime \prime} \mathrm{E}\right)$.

In January 2020, we visited the region and a field investigation was carried out. Many ground fissures and cracks in houses were clearly observed at the southern edges of the two uplift regions where the uplift rate changed rapidly. The cracks occurred early in the period of groundwater overexploitation and developed along the WNW-trending Puning-Tianxin fault (F2 in Fig. 2). Images showing damage to the ground and a house are shown in Fig. 5.

\subsection{Ground subsidence and uplift history}

The IPTA processing with a long-term Sentinel-1 data sequence obtained from July 2015 to November 2019 was carried out to obtain the ground subsidence and uplift history. The annual deformation was obtained from 2016 to 2019 as shown in Fig. 6. The results verify that largescale rapid ground uplift occurred in the Lianjiang Plain in 2019. 


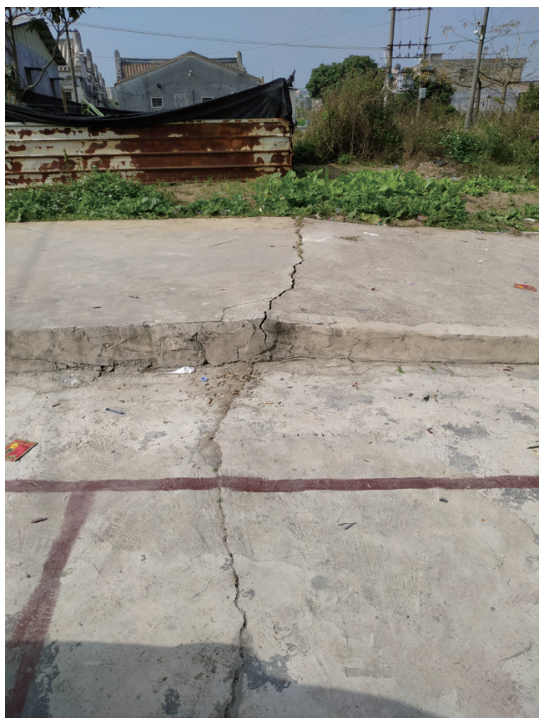

(a)

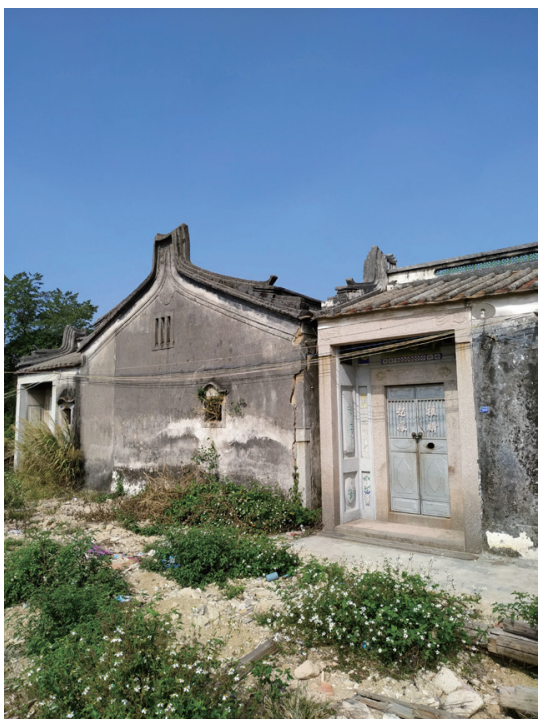

(b)

Fig. 5. (Color) Ground fissures and house crack in ground uplift area edge. (a) Ground fissure and (b) crack in house.

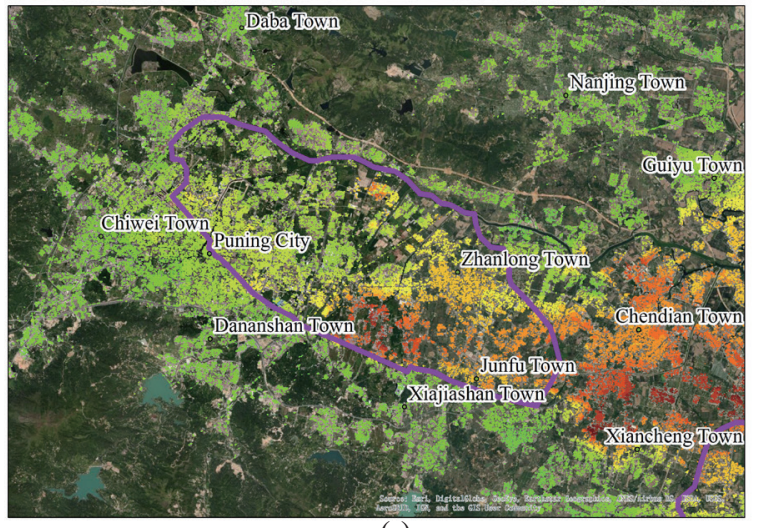

(a)

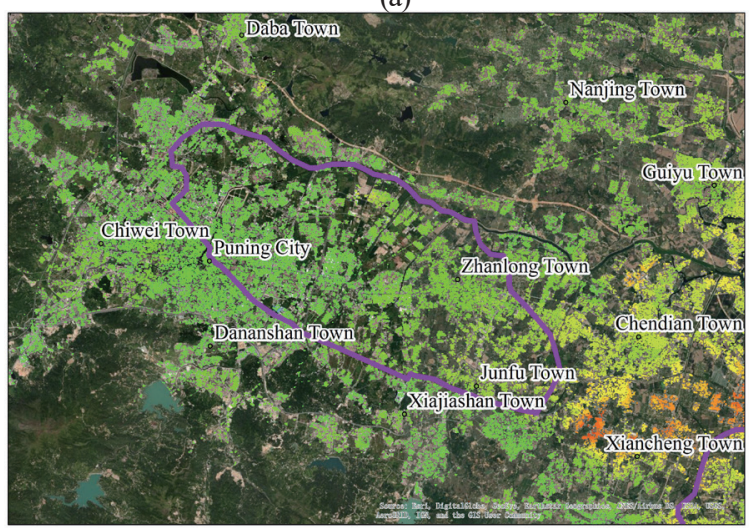

(c)

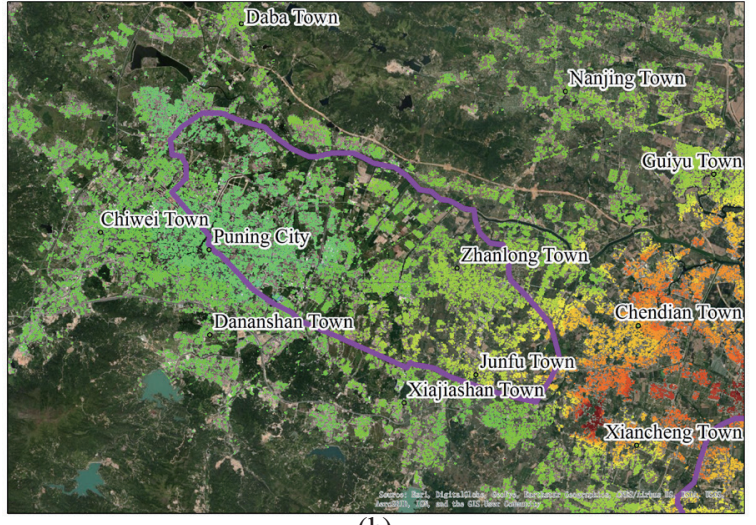

(b)

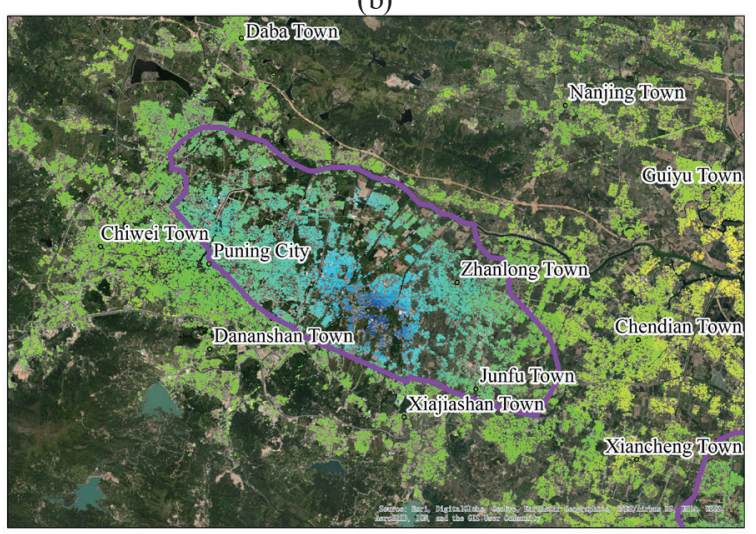

(d)

Fig. 6. (Color) Annual land subsidence/uplift histories of Puning uplift zone in (a) 2016, (b) 2017, (c) 2018, and (d) 2019. The coherent point color legend is the same as that in Fig. 4. 
From November 2015 to November 2016 [Fig. 6(a)], considerable land subsidence occurred in the central part of the Lianjiang Plain, mainly within the region where the thickness of the Quaternary strata is more than $100 \mathrm{~m}$. In addition, subsidence occurred in Heping Town, Tongyu Town, Ximapu Town, and the southern part of Gurao Town along the Lianjiang River. The maximum subsidence rate in Shuangxi Village in the purple frame reached $95 \mathrm{~mm} / \mathrm{a}$, while the Chendian-Xiancheng area on the east had a maximum subsidence rate of more than $100 \mathrm{~mm} / \mathrm{a}$. The region in the purple frame is the zone with the largest uplift in 2019, as described in Sect. 4.1.

The land subsidence velocity in the purple frame decreased from November 2016 to November 2018 [Figs. 6(b) and 6(c)]. The maximum land subsidence rate in the purple box decreased below 50 and $20 \mathrm{~mm} / \mathrm{a}$, respectively, in 2017 and 2018. The subsidence of Shuangxi Village came to a halt, and the subsidence in the Chendian-Xiancheng region and along the banks of the Lianjiang River has also slowed year by year. In 2018, the maximum subsidence rate of Xiancheng Town decreased below $80 \mathrm{~mm} / \mathrm{a}$.

From November 2018 to November 2019 [Fig. 6(d)], the subsidence and uplift showed the same distribution characteristics as those obtained with the RADARSAT-2 data. Ground uplift occurred in Puning County, Xiajiashan Town, Junbu Town, Zhanlong Town in Jieyang City, and Liangying Town in Chaonan District of Shantou City. The maximum uplift rate in Shuangxi Village was about $130 \mathrm{~mm} / \mathrm{a}$, which is close to the result obtained with the RADARSAT-2 data. The maximum uplift rate of Liangying Town was $60 \mathrm{~mm} / \mathrm{a}$, which is slightly lower than the result for RADARSAT-2.

The histories of the two uplift centers obtained by IPTA series analysis are drawn in Fig. 7. Figure 7(a) shows the cumulative deformation of the Puning uplift zone center, indicating that the subsidence occurred from July 2015 to November 2016 and the cumulative subsidence reached more than $100 \mathrm{~mm}$. After a slight uplift from November 2016 to February 2017, the ground surface entered a stable stage, and then there was a small amount of subsidence in March 2018. Land uplift began to gradually occur from July 2018 and accelerated in January 2019. By November 2019, the land had rebounded to near its position in July 2015. Figure 7(b) shows the cumulative deformation history of the center of the Liangying uplift zone. From July 2015 to March 2019, the land surface was basically stable, and then uplift started to occur. By November 2019, the ground surface had uplifted by about $40 \mathrm{~mm}$.

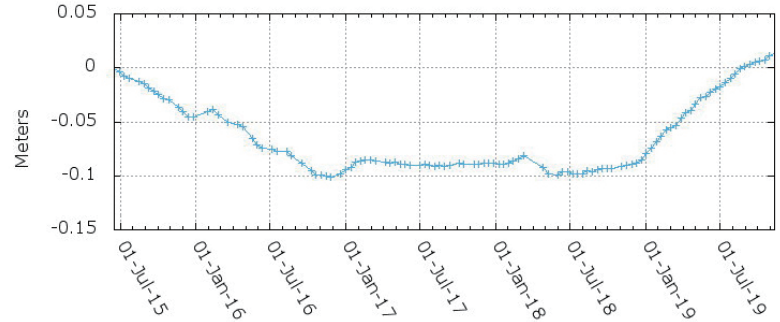

(a)

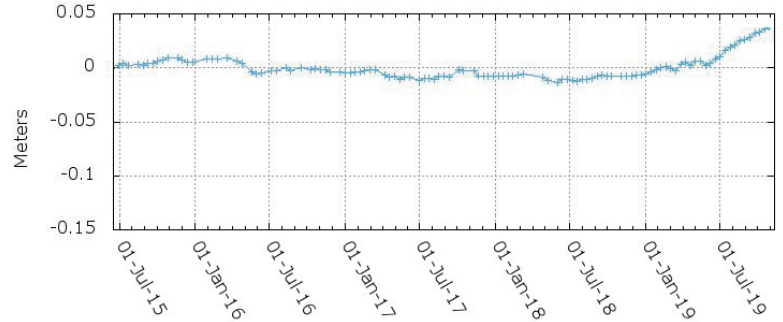

(b)

Fig. 7. (Color online) Cumulative deformation time series of two points with maximum uplift on (a) Puning and (b) Liangying uplift zone centers. 


\subsection{Analysis of land subsidence and uplift mechanism}

The validity of the results obtained from two kinds of radar data showing that Puning City had large-scale and rapid land uplift in 2019 was verified by their very similar ranges and speeds.

The surface uplift zone of Puning City, Xiajiashan Town, Junbu Town, and Zhanlong Town is the region with the fastest uplift in China. Ground subsidence and uplift are mainly caused by local groundwater exploitation. Puning City and Liangying Town are both bases of the Chinese textile industry and there are many private printing and dyeing enterprises. Groundwater pumping during the production of textiles has caused the groundwater level to drop continuously and induced land subsidence. Land subsidence occurred on the north side of the Puning-Tianxin fault, which has strongly contrasting landforms on opposite sides. The upthrown side (southwest side) of the fault is the hilly Dananshan area with an elevation of 300-600 m, while the downthrown side (northeast side) is the flat Lianjiang Plain, ${ }^{(15)}$ so the fault constitutes an obvious geomorphic boundary, resulting in significant differences in land deformation on opposite sides of the fault and the appearance of a ground fissure.

With the implementation of the local government's measures to control the extraction of groundwater, the groundwater source has gradually been replenished and the groundwater level has started to rise. ${ }^{(5)}$ After the recovery of the groundwater, the volume of the soil layers, especially the sand-bearing layer in the Quaternary strata, may recover after water replenishment, then the ground may rise. ${ }^{(16)}$

The zones where land changed from subsidence to uplift are distributed in the region of the Lianjiang Plain where the thickness of the Quaternary strata is the largest, with a deposition thickness greater than $140 \mathrm{~m}$. The drilling data in this zone shows that the main lithology of the Quaternary strata includes gravel-bearing medium-coarse sand, silty fine sand, sand clay, clay, weathered clay, and silt, and there are multiple rhythms or sedimentary cycles in the strata. ${ }^{(10)}$ The multiple compressible layers and thick deposition strata in this area provide conditions for the land surface to undergo subsidence or uplift according to the groundwater level.

\section{Conclusion}

Land subsidence is a slowly evolving geological disaster caused by the overexploitation of underground resources or changes in stratum structure. Large-scale regional land subsidence reflects the bearing capacity of local water resources. Our land deformation survey using InSAR technology showed the following:

(1) In 2019, there was large-scale regional land subsidence and uplift in the Lianjiang Plain. The subsidence was mainly distributed along the two banks of Lianjiang River, and the rate was below $30 \mathrm{~mm} / \mathrm{a}$. At the same time, there were two significant uplift zones centered on Zhanlong Town in Puning and Liangying Town in Shantou, whose uplift rates exceeded 100 and $50 \mathrm{~mm} / \mathrm{a}$, respectively.

(2) The land subsidence in the Lianjiang Plain is due to the overexploitation of groundwater for textile production. The land subsidence area in 2016 became a rebound area in 2019 owing 
to a continuous ban and restrictions on the extraction of groundwater. The thick Quaternary strata and the multiple compressible and expandable soil layers are reasons for the rapid subsidence and uplift of land following a change in groundwater level.

(3) The southern edge of the land subsidence/uplift zone in Puning is restricted by the PuningTianxin fault. The stratigraphic difference on opposite sides of the fault resulted in a large difference in land deformation. The accompanying ground fissures at the southern edge where the land deformation rate is changing rapidly have been impacting the lives of residents.

\section{Acknowledgments}

The authors thank Gamma Remote Sensing for their continuous technical services and ESA for open access to the Sentinel-1 data. This work was supported by the China Geological Survey (project DD20190513) and the National Key Research and Development Program of China (2017YFB0502700).

\section{References}

1 J. Hoffmann and H. A. Zebker: Water Resour. Res. 37 (2001) 1551. https://doi.org/10.1029/2000WR900404

2 Y. Yin, Z. Zhang, and K. Zhang: Chin. J. Geol. Hazard Control 16 (2005) 1. https://doi.org/10.1360/gs050309

3 P. Teatini, M. Ferronato, G. Gambolati, W. Bertoni, and M. Gonella: Environ. Geol. 47 (2005) 831. https://doi. org/10.1007/s00254-004-1215-9

4 H. Wang, X. Zhang, H. Li, W. Ge, and S. Chen: Geol. Rev. 65 (2019) 1229. https://doi.org/10.16509/ j.georeview.2019.05.012

5 G. Wang, J. Zhu, G. You, J. Yu, X. Gong, W. Li, and F. Gou: Eng. Geol. 229 (2017) 13. https://doi.org/10.1016/ j.enggeo.2017.09.006

6 H. A. Zebker and J. Villasenor: IEEE Trans. Geosci. Remote Sens. 30 (1992) 950. https://doi. $\operatorname{org} / 10.1109 / 36.175330$

7 P. A. Rosen, S. Hensley, H. A. Zebker, F. H. Webb, and E. J. Fielding: Geophys. Res. Lett. 101 (1996) 109. https://doi.org/10.1029/96JE01459

8 D. Massonnet, K. Feigl, M. Rossi, and F. Adragna: Nature 369 (1994) 227. https://doi.org/10.1038/369227a0

9 O. Mora, J. J. Mallorqui, and A. Broquetas: IEEE Trans. Geosci. Remote Sens. 41 (2003) 2243. https://doi. org/10.1109/TGRS.2003.814657

10 M. Pietro, G. Giorgia, D, Matthew, P. Daniele, and M. Giovanni: Remote Sens. 10 (2018) 287. https://doi. org/10.3390/rs10020287

11 X. Liu, P. Wang, Z. Lu, K. Gao, H. Wang, C. Jiao, and X. Zhang: Remote Sens. 11 (2019) 580. https://doi. org10.3390/rs11050580

12 Y. Song, W. Chen, H. PAN, Z. Zhang, Z. He, X. Chen, Q. Zeng, Y. She, and J. Zhang: Jilin Univ. (Earth Sci. Ed.). 42 (2012) 154. https://doi.org/10.13278/j.cnki.jjuese. 2012.s1.040

13 Y. Wang, F. Song, Q. Huang, and W. Chen: Earthquake Res. Chin. 17 (2001) 35. https://doi.org/10.3969/ j.issn.1001-4683.2001.01.005

14 H. Wang, D. Zhong, and Y. Zhu: Geospatial Inf. 15 (2017) 49. https://doi.org/10.3969/j.issn.1672-4623.2017.09.016

15 H. Zhao: Acta Oceanolog. Sin. 2 (1983) 107. https://CNKI:SUN:SEAE.0.1983-01-011

16 G. Wang, J. Zhu, D. Zhang, J. Wu, J. Yu, X. Gong, and F. Gou: Q. J. Eng. Geol. Hydrogeol. 53 (2020) 609. https://doi.org/10.1144/qjegh2018-065 


\section{About the Authors}

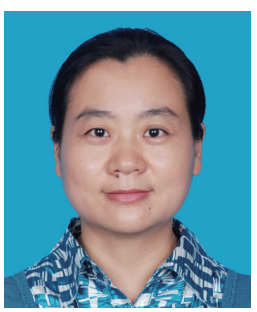

Ling Zhang received her M.S. degree in photogrammetry and remote sensing from China University of Mining and Technology (Beijing) in 2006, with a thesis on SAR interferometry application in land subsidence surveys. From 2006 to 2008, she worked as a technical support engineer of RS and GIS data production. Since 2008, she has worked at China Aero Geophysical Surveying and Remote Sensing Center for Natural Resources. Her research interest is in InSAR application/research on land deformation.

(zling127@qq.com)

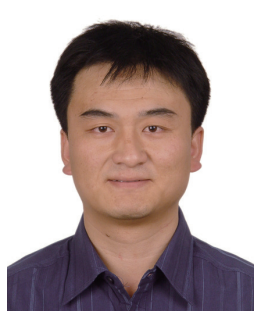

Daqing Ge received his master's degree in photogrammetry and remote sensing and his Ph.D. in geo-environment and engineering in 2005 and 2013, respectively. He has been a professor with China Aero Geophysical Surveying and Remote Sensing Center for Natural Resources since 2016. His research interests include SAR interferometry, remote sensing, and the use of InSAR data for geohazard and geo-environment monitoring. He is a member of the Chinese SAR satellite committee and the deputy chief designer of the LT1SAR mission in China.

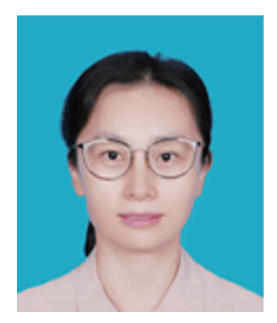

Man Li received her bachelor's and master's degrees in geological engineering from Chang'an University and the Institute of Geology and Geophysics, Chinese Academy of Sciences, China, in 2006 and 2009, respectively. Since 2009, she has been employed at China Aero Geophysical Surveying and Remote Sensing Center for Natural Resources, where she is involved in SAR interferometric data processing and its application to ground deformation monitoring. Currently, she is active in land subsidence monitoring and its development characteristics, especially in the area of mechanisms driving land subsidence.

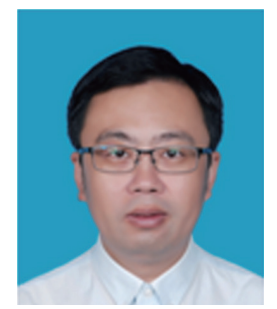

Bin Liu is a senior engineer of China Aero Geophysical Survey and Remote Sensing Center for Natural Resources. He graduated from the Institute of Engineering Mechanics, CEA, in 2013 with a doctorate degree in engineering, and is currently engaged in research on space-borne and ground-based InSAR technologies. (lbin0226@163.com) 


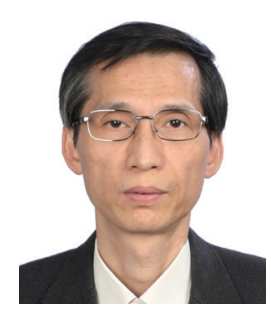

Xiaofang Guo currently is a senior researcher of China Aero Geophysical Survey and Remote Sensing Center for Natural Resources. His research interests include remote sensing image processing and quantitative data analysis for natural resources investigation and assessment by both optical and synthetic aperture radar. (guoxiaofang@mail.cgs.gov.cn)

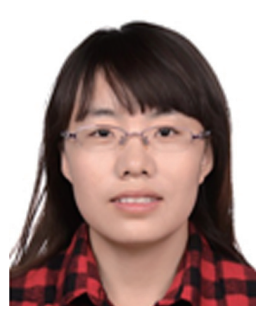

Qiong Wu is an engineer of China Aero Geophysical Survey and Remote Sensing Center for Natural Resources. She received her Ph.D. degree in cartography and geography information systems from Capital Normal University, Beijing, China, in 2019. Her research interests include LiDAR data processing and application, InSAR and its application to disaster monitoring, and the inversion of biophysical parameters. She has published more than 15 papers and won one provincial award and one ministerial award. 